\title{
Maternal and foetal benefits in breast-fed and bottle-fed babies
}

\author{
Singhai A. ${ }^{1}$, Porwal A. ${ }^{2}$ \\ ${ }^{1}$ Dr. Ankur Singhai, Assistant Professor, ${ }^{2}$ Dr. Arpit Porwal, Senior Resident, Department of Paediatrics and Neonatology, \\ both authors are affiliated with L.N. Medical College J.K. Hospital, Bhopal, MP, India.
}

Corresponding Author: Dr. Arpit Porwal, Senior Resident, Department of Paediatrics and Neonatology, L.N. Medical College J.K. Hospital, Bhopal. Email: dr1porwal@gmail.com

\begin{abstract}
Background: It is important to ensure the optimal growth and development of children so that they can effectively contribute towards progress of the nation. Children in their early life are completely dependent for their nutritional requirements on their person both in terms of quantity and quality. This, in term, is influenced by the customs, traditions and beliefs as well as socioeconomics and education status of their parents. Aim: To study the feeding practice and the factors associated with the feeding practice and to compare the health, nutritional status and other benefits of the babies between various groups. To utilize the conclusions derived in future planning and nationwide activities. Materials and Methods: A prospective study was undertaken with 300 breast- and bottle-fed babies and their mothers. They were selected for this study from our OPD using Multistage Stratified Random Sampling Techniques. Keeping the Objectives and natures of the study in view, the 'Descriptive Survey' method of research has been adopted. Results: Out of the 243 babies, majority (46.91\%) were suffered from diarrhea, followed by $38.68 \%$ from fever and $(6.59 \%)$ were suffered from jaundice. Out of the $105,(57.14 \%)$ were suffered from fever, followed by $22.86 \%$ for diarrhea. Similar pattern regarding duration of disease were observed among the breast- and bottle-fed babies. The mean duration of illness was 7.18 days which was more in bottle fed babies (7.58 days) as compared to breast fed babies (6.75 days). Conclusion: Breast feeding can save families as much as Rs. 2500 per months formula costs. Breast feeding can save families even more money by reducing medical costs. For healthier mothers and babies. Experts also agree that breast feeding holds many other benefits for both the mother and infant.
\end{abstract}

Keywords: Breast feeding, Formula costs, Jaundice, Descriptive Survey

\section{Introduction}

Children are the greatest asset, who will shape the future of our country and strengthen the nation. Therefore, to ensure the optimal growth and development of children so that they can effectively contribute towards progress of the nation. Children in their early life are completely dependent for their nutritional requirements on their person both in terms of quantity and quality. This, in term, is influenced by the customs, traditions and beliefs as well as socioeconomics and education status of their parents [1].

Breast feeding is almost universal in over the world, it was also common in the developed countries before advent of industrialism. However, the duration of breast

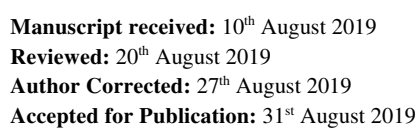

feeding declined slowly due to several factors like education, urbanization, employment and availability of child rearing practice, yet some women resort to feeding of bottle milk to their babies because of various reasons. In recent years, numerous advantages of breast milk have been emphasized based on scientific experimentation [2]. Children are regarded as invaluable treasure of any country, but to prove their worthiness to society it is essential that they must grow well and to an optimal level.

It is an established fact that foundation for physical and mental health for adult life is laid during the formative years of childhood. During infancy mental abilities and social responses are closely related to the motor development of the child which is achieved normally by proper feeding practices. Further, this period is the basis for the future development of the individuals. Feeding practices play an important role in this period for proper 


\section{Original Research Article}

growth and development [3]. Children are valuable assets of a nation and it is their welfare that strengthens its social and economic development. They need to be protected and well looked after if the country is to thrive and prosper in different spheres of human activity. In the present time many developing their people through various family welfare programs of which the child welfare program is one. However, the task has become a challenging one because of the unprecedented growth in population during the last two decades or so, and as far as India is concerned, it is up against this challenge [4].

Unfortunately, millions of children in India and other underdeveloped areas of the world are suffering from malnutrition as a result of poverty. Lack of knowledge, ignorance and superstitions. If a county is to thrive and prosper in all spheres of human activity, then, it should ensure the important elements of child health by immunization, good nutrition, growth promotion and the timely detection and treatment of common childhood disease like diarrhoea and respiratory illnesses [5].

\section{Methodology}

Setting, duration and type of study: This prospective study was conducted in Department of Paediatrics. Study was done in a span of two years.

Sampling methods, sample size calculation: Multistage Stratified Random Sampling Techniques 300 breast- and bottle-fed babies and their mothers were selected for this study from our OPD. Keeping the Objectives and natures of the study in view, the 'Descriptive Survey' method of research has been adopted.

\section{Result}

The breast fed babies were found more in urban areas as compared to rural areas while bottle fed babies were found more in rural areas as compared to urban areas. The breast fed babies were more in joint families as compared to nuclear families while bottle fed babies were more in nuclear families as compared to joint families. The illiterate mothers were more in breast fed babies as compared to bottle fed babies while literate mothers were more in bottle fed babies as compared to breast fed babies. The mothers engaged in household activities were more in breast fed babies as compared to bottle fed babies while mothers engaged in service, teaching and labour were more in bottle fed babies as compared to breast fed babies. In the present study, the mean age of mothers at the time of marriage was 20.54 years which was more among the mothers of bottle fed babies (21.05 years) as compared to mothers of breast fed babies (20.53 years).

Out of total respondents, majority of them (56.67\%) were belonged to families having monthly income below Rs. 10000 . In the present study, the mean family monthly income was Rs. 11404.33 which was more the bottle-fed bottles (Rs. 12847.33) as compared to breast fed babies (Rs. 9961.33). The males babies were more among the breast fed babies as compared to bottle fed while female babies were more among the bottle fed as compared to breast fed. The normal delivery born was more among the breast-fed babies as compared to bottle fed babies while abnormal delivery born was 


\section{Original Research Article}

more among the bottle-fed babies as compared to breast fed babies. Out of the 243 babies, majority (46.91\%) were suffered from diarrhea, followed by 38.68\% from fever and minimum (6.59\%) were suffered from jaundice. Out of the 105 breast fed babies, majority (57.14\%) were suffered from fever, followed by $22.86 \%$ for diarrhea and minimum $(9.52 \%)$ were suffered from jaundice while out of the bottle bed babies, majority $(50.72 \%)$ were suffered from diarrhea, followed by $39.13 \%$ from fever and minimum (4.35\%) were suffered from jaundice. Out of 243 babies, suffering from disease, majority (48.56\%) were suffering less than 5 days, followed by $(40.33 \%)$ of $6-10$ days and the minimum $(7.18 \%)$ were suffering 16 days and more. Similar pattern regarding duration of disease were observed among the breast- and bottle-fed babies. The mean duration of illness was 7.18 days which was more in bottle fed babies (7.58 days) as compared to breast fed babies.

The good health at the time of birth was more among the breast-fed babies as compared to bottle fed babies while the poor health at the time of birth was more among the bottle-fed babies as compared to breast fed babies. The mean weight of breast fed babies was more at the age of 6,7,8,9,10,11 and months as compared to bottle fed babies in the present study. The mean weight of breast fed babies $(8.01 \mathrm{kgs})$ was found more as compared to bottle fed babies $(6.79 \mathrm{kgs})$. The mean chest circumference of breast fed babies was more at the age of 6,7,8,9,10,11 and 12 months as compared to bottle fed babies in the present study. The mean chest circumference of breast fed babies $(44.59 \mathrm{cms})$ was found more as compared to bottle fed babies $(43.45 \mathrm{cms})$ The mean had circumference of breast fed babies was more at the of $6,7,8,9,10,11$ and 12 months as compared to bottle fed babies in the present study. The mean had circumference of breast-fed babies $(43.61 \mathrm{cms})$ was found more as compared to bottle fed babies $(42.32 \mathrm{cms})$.

Table-1: Distribution of breast-and bottle-fed babies according to occupation of their mothers.

\begin{tabular}{|c|c|c|c|c|c|c|}
\hline Mother's education & \multicolumn{2}{|c|}{ Feeding practice } & \multicolumn{2}{c|}{ Bottle } & $\%$ \\
\hline & \multicolumn{2}{|c|}{ Breast } & No. & $\%$ & No. & $\%$ \\
\hline Nervice & 3 & 2.00 & 5 & 3.33 & 8 & 2.67 \\
\hline Labour & 2 & 1.33 & 0 & 0.00 & 2 & 0.66 \\
\hline Teaching & 3 & 2.00 & 14 & 9.33 & 17 & 5.67 \\
\hline Housewife & 142 & 94.67 & 131 & 87.34 & 273 & 91.00 \\
\hline Total & $\mathbf{1 5 0}$ & $\mathbf{5 0 . 0 0}$ & $\mathbf{1 5 0}$ & $\mathbf{5 0 . 0 0}$ & $\mathbf{3 0 0}$ & $\mathbf{1 0 0 . 0 0}$ \\
\hline
\end{tabular}

Table-2: Distribution according to mother's age at marriage.

\begin{tabular}{|c|c|c|c|c|c|c|}
\hline \multirow{3}{*}{$\begin{array}{l}\text { Mother's age at } \\
\text { marriage in years }\end{array}$} & \multicolumn{6}{|c|}{ Feeding practice } \\
\hline & \multicolumn{2}{|c|}{ Breast } & \multicolumn{2}{|c|}{ Bottle } & \multicolumn{2}{|c|}{ Total } \\
\hline & No. & $\%$ & No. & $\%$ & No. & $\%$ \\
\hline $15-20$ & 74 & 49.33 & 58 & 38.67 & 132 & 44.00 \\
\hline $20-25$ & 67 & 44.67 & 75 & 50.00 & 142 & 47.33 \\
\hline $25-30$ & 9 & 6.00 & 17 & 11.33 & 26 & 8.67 \\
\hline Total & 150 & 50.00 & 150 & 50.00 & 300 & 100.00 \\
\hline Mean & \multicolumn{2}{|c|}{20.03} & \multicolumn{2}{|c|}{21.05} & \multicolumn{2}{|c|}{20.54} \\
\hline SD & \multicolumn{2}{|c|}{2.59} & \multicolumn{2}{|c|}{2.82} & \multicolumn{2}{|c|}{2.75} \\
\hline $\mathrm{T}$ & \multicolumn{4}{|c|}{3.263} & & \\
\hline $\mathrm{P}$ & \multicolumn{4}{|c|}{$<0.05$} & & \\
\hline
\end{tabular}


Table-3: Distribution according to family monthly income

\begin{tabular}{|c|c|c|c|c|c|c|}
\hline \multirow[t]{3}{*}{ Family monthly in Rs. } & \multicolumn{6}{|c|}{ Feeding practice } \\
\hline & \multicolumn{2}{|c|}{ Breast } & \multicolumn{2}{|c|}{ Bottle } & \multicolumn{2}{|c|}{ Total } \\
\hline & No. & $\%$ & No. & $\%$ & No. & $\%$ \\
\hline $0-10000$ & 99 & 66.00 & 74 & 49.33 & 173 & 56.67 \\
\hline $10000-20000$ & 26 & 17.33 & 43 & 28.67 & 69 & 23.00 \\
\hline 20000 and above & 25 & 16.67 & 33 & 22.00 & 58 & 19.57 \\
\hline Total & 150 & 50.00 & 150 & 50.00 & 300 & 100.00 \\
\hline Mean & \multicolumn{2}{|c|}{9961.33} & \multicolumn{2}{|c|}{12847.33} & \multicolumn{2}{|c|}{11404.33} \\
\hline SD & \multicolumn{2}{|c|}{8620.90} & \multicolumn{2}{|c|}{9436.04} & \multicolumn{2}{|c|}{9152.13} \\
\hline $\mathrm{T}$ & \multicolumn{4}{|c|}{2.766} & & \\
\hline $\mathrm{P}$ & \multicolumn{4}{|c|}{$<0.05$} & & \\
\hline
\end{tabular}

Table-4: Mean height according to age

\begin{tabular}{|c|c|c|c|c|c|c|c|c|}
\hline \multirow{3}{*}{$\begin{array}{l}\text { Age in } \\
\text { months }\end{array}$} & \multicolumn{6}{|c|}{ Mean height in cms. and feeding practice } & \multicolumn{2}{|c|}{ Statistical values } \\
\hline & \multicolumn{3}{|c|}{ Breast } & \multicolumn{3}{|c|}{ Bottle } & \multirow[b]{2}{*}{$\mathrm{t}$} & \multirow[b]{2}{*}{$\mathrm{P}$} \\
\hline & No. & Mean & $\mathrm{SD}$ & No. & Mean & SD & & \\
\hline 6 & 19 & 65.00 & 0.92 & 9 & 61.89 & 0.31 & 9.796 & $<0.05$ \\
\hline 7 & 57 & 66.89 & 1.05 & 30 & 63.10 & 1.68 & 12.904 & $<0.05$ \\
\hline 8 & 13 & 69.38 & 0.92 & 24 & 65.62 & 3.01 & 4.370 & $<0.05$ \\
\hline 9 & 43 & 71.63 & 3.16 & 43 & 66.60 & 4.16 & 6.314 & $<0.05$ \\
\hline 10 & 5 & 73.60 & 0.80 & 11 & 68.09 & 0.90 & 11.707 & $<0.05$ \\
\hline 11 & 6 & 74.33 & 0.47 & 20 & 71.75 & 1.61 & 3.827 & $<0.05$ \\
\hline 12 & 7 & 75.43 & 0.90 & 13 & 71.85 & 1.66 & 5.261 & $<0.05$ \\
\hline Total & 150 & 69.15 & 3.60 & 150 & 66.71 & 4.20 & 5.402 & $<0.05$ \\
\hline
\end{tabular}

Table-5: Mean weight according to age

\begin{tabular}{|c|c|c|c|c|c|c|c|c|}
\hline \multirow{3}{*}{$\begin{array}{l}\text { Age in } \\
\text { months }\end{array}$} & \multicolumn{6}{|c|}{ Mean weight in cms. and feeding practice } & \multicolumn{2}{|c|}{ Statistical values } \\
\hline & \multicolumn{3}{|c|}{ Breast } & \multicolumn{3}{|c|}{ Bottle } & \multirow[b]{2}{*}{$\mathrm{t}$} & \multirow[b]{2}{*}{$\mathrm{P}$} \\
\hline & No. & Mean & $\mathrm{SD}$ & No. & Mean & SD & & \\
\hline 6 & 19 & 6.37 & 0.48 & 9 & 5.67 & 0.47 & 3.627 & $<0.05$ \\
\hline 7 & 57 & 7.14 & 0.69 & 30 & 6.50 & 1.09 & 3.340 & $<0.05$ \\
\hline 8 & 13 & 8.08 & 0.62 & 24 & 6.67 & 0.69 & 6.140 & $<0.05$ \\
\hline 9 & 43 & 9.00 & 0.61 & 43 & 6.70 & 1.56 & 9.004 & $<0.05$ \\
\hline 10 & 5 & 9.80 & 0.75 & 11 & 6.82 & 0.39 & 10.646 & $<0.05$ \\
\hline 11 & 6 & 9.67 & 0.47 & 20 & 7.45 & 1.12 & 4.679 & $<0.05$ \\
\hline 12 & 7 & 10.71 & 0.45 & 13 & 7.69 & 1.32 & 5.811 & $<0.05$ \\
\hline Total & 150 & 8.01 & 1.36 & 150 & 6.79 & 1.26 & 8.095 & $<0.05$ \\
\hline
\end{tabular}


Table-6: Mean chest circumference according to age

\begin{tabular}{|c|c|c|c|c|c|c|c|c|}
\hline \multirow{2}{*}{$\begin{array}{c}\text { Age in } \\
\text { months }\end{array}$} & \multicolumn{9}{|c|}{ Mean chest circumference in cms. and feeding practice } & \multicolumn{3}{c|}{ Bottle } & & \\
\hline & \multicolumn{3}{|c|}{ Breast } & No. & Mean & SD & t & P \\
\hline & No. & Mean & SD & No. values \\
\hline 6 & 19 & 42.11 & 1.25 & 9 & 41.22 & 0.63 & 2.005 & $<0.05$ \\
\hline 7 & 57 & 44.23 & 0.92 & 30 & 42.30 & 2.84 & 4.685 & $<0.05$ \\
\hline 8 & 13 & 44.85 & 0.86 & 24 & 43.42 & 1.98 & 2.468 & $<0.05$ \\
\hline 9 & 43 & 45.33 & 0.86 & 43 & 43.91 & 2.00 & 4.277 & $<0.05$ \\
\hline 10 & 5 & 45.60 & 0.49 & 11 & 44.18 & 1.53 & 1.995 & $<0.05$ \\
\hline 11 & 6 & 45.83 & 0.69 & 20 & 43.60 & 1.80 & 2.935 & $<0.05$ \\
\hline 12 & 7 & 47.43 & 0.73 & 13 & 45.38 & 1.64 & 5.349 & $<0.05$ \\
\hline Total & $\mathbf{1 5 0}$ & $\mathbf{4 4 . 5 9}$ & $\mathbf{1 . 5 2}$ & $\mathbf{1 5 0}$ & $\mathbf{4 3 . 4 5}$ & $\mathbf{2 . 2 9}$ & $\mathbf{5 . 0 8 0}$ & $<\mathbf{0 . 0 5}$ \\
\hline
\end{tabular}

Table-7: Distribution according to reason for initiating breast milk

\begin{tabular}{|l|c|c|c|c|c|c|}
\hline \multicolumn{1}{|c|}{$\begin{array}{c}\text { Reason of initiating } \\
\text { breast milk }\end{array}$} & \multicolumn{2}{c}{ Feeding practice } & \multicolumn{2}{c|}{ Bottle } \\
\hline & \multicolumn{2}{|c|}{ Breast } & No. & $\%$ & No. \\
\hline No. & 9 & 6.00 & 21 & 14.00 & 30 & 10.00 \\
\hline Nather mothers do it & 52 & 34.67 & 30 & 20.00 & 82 & 27.33 \\
\hline Pure and clean & 16 & 10.67 & 2 & 1.33 & 18 & 6.00 \\
\hline Automatic sterile & 3 & 2.00 & 15 & 10.00 & 18 & 6.00 \\
\hline Free of cost & 5 & 3.33 & 3 & 2.00 & 8 & 2.67 \\
\hline Convenient & 7 & 4.67 & 12 & 8.00 & 19 & 6.33 \\
\hline Advised by relatives & 21 & 14.00 & 12 & 8.00 & 33 & 11.00 \\
\hline To develop immunity & 26 & 17.33 & 52 & 34.67 & 78 & 26.00 \\
\hline Method of contraception & 11 & 7.33 & 3 & 2.00 & 14 & 4.67 \\
\hline \multicolumn{1}{|c|}{ Total } & $\mathbf{1 5 0}$ & $\mathbf{5 0 . 0 0}$ & $\mathbf{1 5 0}$ & $\mathbf{5 0 . 0 0}$ & $\mathbf{3 0 0}$ & $\mathbf{1 0 0 . 0 0}$ \\
\hline
\end{tabular}

Table-8: Distribution according to use of colostrum

\begin{tabular}{|c|c|c|c|c|c|c|}
\hline \multirow[t]{3}{*}{ Use of colostrum } & \multicolumn{6}{|c|}{ Feeding practice } \\
\hline & \multicolumn{2}{|c|}{ Breast } & \multicolumn{2}{|c|}{ Bottle } & \multicolumn{2}{|c|}{ Total } \\
\hline & No. & $\%$ & No. & $\%$ & No. & $\%$ \\
\hline Yes & 141 & 94.00 & 111 & 74.00 & 252 & 84.00 \\
\hline No & 9 & 6.00 & 39 & 26.00 & 48 & 16.00 \\
\hline Total & 150 & $\mathbf{5 0 . 0 0}$ & 150 & $\mathbf{5 0 . 0 0}$ & 300 & 100.00 \\
\hline
\end{tabular}


Table-9: Reason for using bottle feeding by their mothers.

\begin{tabular}{|c|c|c|}
\hline Reason for using bottle feeding & \multicolumn{2}{|c|}{ Respondents } \\
\hline & No. & $\%$ \\
\hline Mother sick & 79 & 52.67 \\
\hline Insufficient milk & 51 & 34.00 \\
\hline Weak child & 4 & 2.66 \\
\hline Working mother & 16 & 10.67 \\
\hline Total & $\mathbf{1 5 0}$ & $\mathbf{1 0 0 . 0 0}$ \\
\hline
\end{tabular}

Table-10: Distribution according to disease.

\begin{tabular}{|c|c|c|c|c|c|c|}
\hline Name of disease & \multicolumn{3}{|c|}{ Feeding practice } \\
\hline & \multicolumn{2}{|c|}{ Breast } & \multicolumn{2}{c|}{ Bottle } & \multicolumn{2}{c|}{ Total } \\
\hline & No. & $\%$ & No. & $\%$ & No. & $\%$ \\
\hline Diarrhoea & 24 & 22.86 & 70 & 50.72 & 94 & 38.68 \\
\hline Fever & 60 & 57.14 & 54 & 39.13 & 114 & 46.91 \\
\hline Pneumonia & 11 & 10.48 & 8 & 58.00 & 19 & 7.82 \\
\hline Jaundice & 10 & 9.52 & 6 & 4.35 & 16 & 6.59 \\
\hline Total & $\mathbf{1 0 5}$ & $\mathbf{4 3 . 2 1}$ & $\mathbf{1 3 8}$ & $\mathbf{5 6 . 7 9}$ & $\mathbf{2 4 3}$ & $\mathbf{1 0 0 . 0 0}$ \\
\hline
\end{tabular}

\section{Discussion}

This paper discusses the observations of the present study in the light of earlier studies conducted so far and certain other justification as per the observations and exhaustive literature studied by the investigator. The discussions presented are corollary to the objectives and major findings of the study. Appropriate analysis and discussion are necessary to make selection, administration and score worthwhile.

Not much, rather very little work has been done in dealing with breast- and bottle-fed babies in India. However, whatsoever researches conducted in India and abroad are reviewed and presented for discussion within the present findings. The researcher indeed has very limited resources from which she could seek help while framing her discussion mater. Thus, whatsoever analysis and reason for the results are given, are in the light of researcher's mental status and understanding of the subject.

All care has been taken in analyzing each and every result with open mind and broadened horizons. Throughout the research the researcher has taken utmost precaution to avoid ambiguity and superficiality of thoughts. On the basis of analysis and interpretation of data discussed in the previous chapter, the major findings have been discussed as given below:
In the present study, 300 babies and their mothers were selected. Out of selected babies, 50\% each were breast fed and bottle fed respectively and $50.00 \%$ each were belonging to urban and rural areas respectively. The breast-fed babies were found more in urban areas as compared to rural areas while bottle fed babies were found more in rural areas as compared to urban areas.

Cunningham AS et al studied morbidity in breast-fed and artificially fed infants. II. The study enumerated advantages of breast-feeding in reducing morbidity shown in a group of rural infants. The protection afforded by breast-feeding is greatest during the early months, increases with the duration of breast-feeding, and appears to be more striking for serious illness. It operates independently of the effect of associated factors such as socio-educational status, family size, day-care exposure, and birth weight [1].

Similar studies were done by Lucas A, St James et al. They made observations on crying, fussing and colic behavior in breast-and bottle-fed infants. Early human development. Persistent infant crying and "colic" have been linked in some studies to feeding, but this association has not been tested in a planned longitudinal study comparing breast- with formula fed babies. Validated maternal diaries of infant behaviors were 


\section{Original Research Article}

used, kept for three days at both two and six weeks of infant age, in a comparative study of 97 breast- or formula fed babies. These findings link the timing of the infant crying peak to the mode of feeding. Our data indicate that any regimen designed to reduce crying should commence in the neonatal period in formula fed infants [2].

Sauls HS et al studied the potential effect of demographic and other variables in studies comparing morbidity of breast-fed and bottle-fed infants. Selfselection introduces complex variables encompassing much more than milk source used for infant feeding. Reasons for selecting breast or bottle feeding relate to demographic, socioeconomic, educational, ethnic, cultural, and psychological factors, as well as maternal and infant physical and emotional health. Many of the differences in the maternal populations may affect infant care practices, access to medical care, and infant health status [3].

A Randomized Clinical Trial was done by Valerie J. Flaherman on the effect of early limited formula on breastfeeding. He determined whether using $10 \mathrm{~mL}$ formula after each breastfeeding before copious maternal milk production affects breastfeeding duration, readmission, and intestinal microbiota through 1 month of age. Outcomes assessed through 1 month included breastfeeding duration, readmission, and intestinal microbiota. ELF did not interfere with breastfeeding at 1 month, breastfeeding without formula at 1 month, or intestinal microbiota.

ELF may be an important therapeutic option for newborns with the potential to reduce readmission rates. Substance fed and mode of breast milk delivery have different contributions to infant health depending on the health outcome of interest. Feeding at the breast may be advantageous compared with expressed milk feeding for reducing the risk of otitis media, and breast milk feeding compared with formula may reduce the risk of diarrhea [4].

Dollberg $\mathrm{S}$ et al did a comparison of intakes of breastfed and bottle-fed infants during the first two days of life. They compared the spontaneous formula intake of unrestricted formula-fed infants to that of breast-fed infants over the first 48 hours of life. They hypothesized that 1) spontaneous formula intake of unrestricted infants is much higher than that of breast-fed infants and 2) spontaneous formula intake correlates positively with gestational age or birthweight. Breast-fed infants lost significantly more weight on Day 2. In multiple regression, when the dependent variable was the second-day intake, the significant independent variables were group (higher intake in the formula-fed group), weight loss (the higher the weight loss, the lower the intake), and first-day intake (the higher the first-day intake, the higher the second-day intake).It was concluded that newborn infants offered formula ad libitum every four hours consumed much larger amounts than breast-fed infants fed according to the same schedule. In addition, weight loss was more marked in breast-fed infants on day 2 of life [5].

Butte NF et al did work on human milk intake and growth in exclusively breast-fed infants. Milk intake and growth in 45 exclusively breast-fed infants were documented during the first 4 months of life. Energy and protein intakes were substantially less than current nutrient allowances. Energy intake declined significantly from $110 \pm 24 \mathrm{kcal} / \mathrm{kg} /$ day at 1 month to $71 \pm 17 \mathrm{kcal} / \mathrm{kg} / \mathrm{day}$ at 4 months. Protein intake decreased from $1.6 \pm 0.3 \mathrm{gm} / \mathrm{kg} /$ day at 1 month to $0.9 \pm 0.2 \mathrm{gm} / \mathrm{kg} / \mathrm{day}$ at 4 months. Infant growth progressed satisfactorily, compared with National Center for Health Statistics standards. A reevaluation of energy and protein intakes and allowances during infancy is merited [6].

Ogawa $\mathrm{K}$ et al studied volatile fatty acids, lactic acid, and $\mathrm{pH}$ in the stools of breast-fed and bottle-fed infants. They measured fecal $\mathrm{pH}$, volatile fatty acids (VFA), and lactic acid concentrations in 67 healthy infants ranging in age from 1 to 5 months. Fecal VFA concentration and $\mathrm{pH}$ of bottle-fed infants (groups 2 and 3) were significantly higher and lactic acid concentrations significantly lower than those of the breast-fed group. Groups 4 and 5 showed significantly higher $\mathrm{pH}$ and propionic acid concentration, and lower lactic acid concentration than Group 1 did. On the other hand, the addition of formula or cow's milk to the human milk was sufficient to alter the profile of VFA, the $\mathrm{pH}$, and the lactic acid concentration of breast-fed infants' stools. Low $\mathrm{pH}$, low VFA, and high lactic acid concentrations make the colonic content of breast-fed babies an environment favorable for Bifido-bacteria growth, and this is probably the main protective factor against gastrointestinal infections [7].

In a comparative study, Adebonojo FO et al did a comparison of artificial vs breast feeding in relation to infant health in a middle-class American community of 113 infants of affluent and well-educated parents in the same environment, 52 were breast fed and 61 artificially fed. No significant differences could be found between 


\section{Original Research Article}

the two groups with respect to a variety of standard clinical measures of health and wellbeing. Where poor hygiene is not a factor, mother's milk per se appears to offer no advantage over present-day artificial infant foods [8]. Gruskay FL. studied comparison of breast, cow, and soy feedings in the prevention of onset of allergic disease in a prospective study. Study was designed to determine if the food ingested during the first months of life is related to the development of atopy in the offspring of allergic families.

Breast fed infants were found to have approximately one-half the incidence of atopy of cow's milk or soy formula fed infants from atopic families when followed for up to 15 years. Soy feeding produced no advantage over cow's milk in the prophylaxis of allergic disease. There was a threefold increase in clinically apparent atopic disease in offspring of allergic families when compared to controls but only a two-fold increase if the infant was breast fed. These results support the hypothesis that breast feeding and delay of exposure to known allergens may reduce the frequency of clinical allergic disease in the offspring of allergic families [9].

Faber HK, Sutton TL. Et al did a statistical comparison of breast-fed and bottle-fed babies during the first year: with special reference to gain in weight and to morbidity They revealed alarming hazards of bottle feeding, and it formed the basis of teaching to medical students, mothers and the public generally, that breast feeding under practically all conditions and continued for the most protracted period possible is preferable to bottle feeding. They also concluded that that breast-fed babies are healthier, more resistant to infection and stronger, have firmer flesh, and are less subject to various nutritional disturbances [10].

The comparative study on mortality of Breast Fed and Bottle Fed Infants by Mannheimer E was based on all infants who died in Stockholm during the years 1943-47 between the ages of 2 and 12 months. The deaths in the first month of life were omitted since feeding could not be a factor of importance in the cause of death. Children who were solely breast fed or had only a small additional supplementary feeding up to the age of 6 months were regarded as breast fed. Bottle-fed babies were those exclusively fed on cow's milk from the age of 2 months. The mixed-feeding group were an intermediate group. Breast-fed babies attended the welfare centers more regularly than bottle-fed babies, and regular attendance at the welfare centers may have had some effect on feeding since the centers favored breast feeding. The bottle-fed infants had a death rate between 2 and 12 months of 10.95 per 1, 000 compared with 4.63 for the. breast-fed group. The death rate for the mixed-feeding group of infants was lower than that of the breast-fed infants. The rate of growth does not appear to be related to type of feeding since the average weight at the end of the first year of life was the same for the 3 groups. Neither is growth related to the income groups of the parents. The age of mother at delivery was similar in each of the 3 groups of feeding [11].

Hoey C, Ware JL et al did work on economic advantages of breast-feeding in an HMO in a setting of a pilot study. They performed a pilot study on newborns randomly chosen from term singleton deliveries born to mothers in an HMO. Medical care and costs for the first 12 months were retrospectively analyzed, including office visits, drug prescriptions, and hospitalizations. Both groups had similar numbers of office visits and pharmacy costs.

Breast-fed infants had fewer inpatient admissions and their average total medical costs were \$200 less than those of bottle-fed infants. Extrapolating to the total number of deliveries during this period, an increase in breast-feeding from the current rate $(17 \%)$ to the Healthy People 2000 goal $(50 \%)$ could save up to $\$ 140,000$ annually. Breast feeding can save families as much as Rs. 2500 per months formula costs [12].

Sánchez-Molins et al did comparative study of the craniofacial growth depending on the type of lactation received. First, the upper incisors were found to be protruded in the bottle-fed group. Second, subjects belonging to the breast-fed group displayed a brachycephalic mandible arch, while those fed with bottle had a dolichocephalic Steiner mandibular plane. Third, both facial depth and distance of the pogonion to the perpendicular nasion presented a certain tendency to a retruded mandibular bone in the bottle-fed group. And fourth, the frequency of use of dummy and thumb suction were greater in the bottle feed group, without statistical significance. They concluded that in addition to the multiple advantages that mother's milk offers to newborns, breastfeeding also helps correct orofacial development [13].

Moral A, Bolibar I et al did comparison between bottle feeding and breastfeeding and mechanics of sucking. They assessed the mechanics of sucking in exclusive breastfeeding, exclusive bottle feeding, and mixed feeding. The hypothesis established was that physiological pattern for suckling movements differ depending on the type of feeding. Babies with 
Original Research Article

breastfeeding have suckling movements at the breast that are different from the movements of suckling a type of babies fed with bottle. Children with mixed feeding mix both types of suckling movements. The mechanics of sucking in mixed feeding lay outside the range of equivalence comparing bottle feeding with breastfeeding, although differences were small.

Children with mixed feeding would mix both types of sucking movements (breastfeeding and bottle feeding) during the learning stage and adopt their own pattern [14].

There is need for more cautious use of the available data and investigators must seek ways to design future studies to take into account the differences between breast-feeding and bottle-feeding mothers that affect both reported and actual infant morbidity.

\section{Limitation of the present study}

1. Small sample size

2. Chances of bias

3. Single center trial

\section{Conclusion}

\section{Benefits for mothers}

- Fewer incidents of pre-menopausal ovarian and breast cancer.

- Sense of fulfillment.

- Eating more while potentially losing weight.

- Calming effect of nursing yours infant and baby.

- Mothers and babies are more relaxed.

- Saving a family more than Rs 30,000 over buying formula during the first year of life.

- Less time missed from work because of improved health of baby.

\section{Benefits for babies}

- Fewer ear and respiratory infections.

- Disease preventing immunities are passed from mother to child.

- Reduced incidence of blood infection and meningitis.

- Lower mortality rate for infants.

- Assures contact with mother.

- Fewer incidents of serious diarrhoea.

\section{What this study adds to existing knowledge?}

Studies published to date have not quantified these confounding effects and other potential biases in comparing morbidity of breast- and bottle-fed infants and the relationship between milk source and incidence of infantile disease remains in question. There is need for more cautious use of the available data and investigators must seek ways to design future studies to take into account the differences between breast-feeding and bottle-feeding mothers that affect both reported and actual infant morbidity.

\section{Author's contribution}

Dr. Ankur Singhai: Concept and design of the study.

Dr. Arpit Porwal: Data collection and references.

Funding: Nil, Conflict of interest: None initiated, Permission from IRB: Yes

Ethical approval: Taken

\section{References}

1. Cunningham AS. Morbidity in breast-fed and artificially fed infants. II. J Pediatr. 1979;95(5 Pt 1): 685-689. doi:10.1016/s0022-3476(79)80711-8

2. Lucas A, St James-Roberts I. Crying, fussing and colic behaviour in breast-and bottle-fed infants. Early Human Develop. 1998; 53(1):9-18. doi:10.1016/s03783782 (98)00032-2

3. Sauls HS. Potential effect of demographic and other variables in studies comparing morbidity of breast-fed and bottle-fed infants. Pediat. 1979;64(4):523-527.

4. Flaherman VJ, Narayan NR, Hartigan-O'Connor D, Cabana MD, McCulloch CE, Paul IM. The Effect of Early Limited Formula on Breastfeeding, Readmission, and Intestinal Microbiota: A Randomized Clinical Trial. J Pediatr. 2018;196:84-90.e1. doi: 10.1016/j.jpeds.2017. 12.073. Epub 2018 Mar 14.

5. Dollberg S, Lahav S, Mimouni FB. A comparison of intakes of breast-fed and bottle-fed infants during the first two days of life. J Am Coll Nutr. 2001; 20 (3): 209-211.

6. Butte NF, Garza C, Smith EO, Nichols BL. Human milk intake and growth in exclusively breast-fed infants. J Pediatr. 1984; 104(2):187-195. doi:10.1016/ s0022-3476(84)80990-7 
Original Research Article

7. Ogawa K, Ben RA, Pons S, Bustos LF. Volatile fatty acids, lactic acid, and $\mathrm{pH}$ in the stools of breast-fed and bottle-fed infants. J Pediat Gastroenterol Nutri. 1992;15 (3): 248-252.

8. Adebonojo FO. Artificial vs breast feeding: relation to infant health in a middle-class American community. Clinic Pediat. 1972;11(1):25-29.

9. Gruskay FL. Comparison of breast, cow, and soy feedings in the prevention of onset of allergic disease: a 15-year prospective study. Clin Pediatr (Phila). 1982; 21(8):486-491. DOI:10.1177/000992288202100807

10. Faber HK, Sutton TL. A statistical comparison of breast-fed and bottle-fed babies during the first year: with special reference to gain in weight and to morbidity. Am J Dis Child. 1930;40(6):1163-1176. doi:10.1001/archpedi.1930.01940060003001
11. Mannheimer E. Mortality of breast fed and bottlefed infants; a comparative study. Acta Genet Stat Med. 1955;5(2):134-163.

12. Hoey C, Ware JL. Economic advantages of breastfeeding in an HMO: setting a pilot study. Am J Manag Care. 1997;3(6):861-865.

13. Sánchez-Molins M, Grau JC, Lischeid CG, Ustrell JT. Comparative study of the craniofacial growth depending on the type of lactation received. Europe $\mathrm{J}$ Paediat Dentist. 2010;11(2):87-92.

14. Moral A, Bolibar I, Seguranyes G, Ustrell JM, Sebastiá G, Martínez-Barba C, et al. Mechanics of sucking: comparison between bottle feeding and breastfeeding. BMC Pediatr. 2010;10:6. doi: 10.1186/ 1471-2431-10-6.

\section{How to cite this article?}

Singhai A, Porwal A. Maternal and foetal benefits in breast-fed and bottle-fed babies. Int J Pediatr Res. 2019;6(08): 401-410.doi:10.17511/ijpr. 2019.i08.03 